\title{
Notes on the vocalizations of Greyish Saltator (Saltator coerulescens)
}

Peter Boesman

In the following we briefly analyze and compare voice of the different races of Greyish Saltator (Saltator coerulescens). We also try to quantify the extent of any vocal differences using the criteria proposed by Tobias et al. (2010), as a support for taxonomic review. We have made use of sound recordings available on-line from Xeno Canto (XC).

Vocally there seem to be three distinct groups:

1. The Northern group (includes vigorsii, plumbiceps, grandis, yucatanensis, hesperis and brevicaudus)

This group has two main song-like vocalizations:

* a whistled song consisting of a short phrase ending with a slurred rising whistle
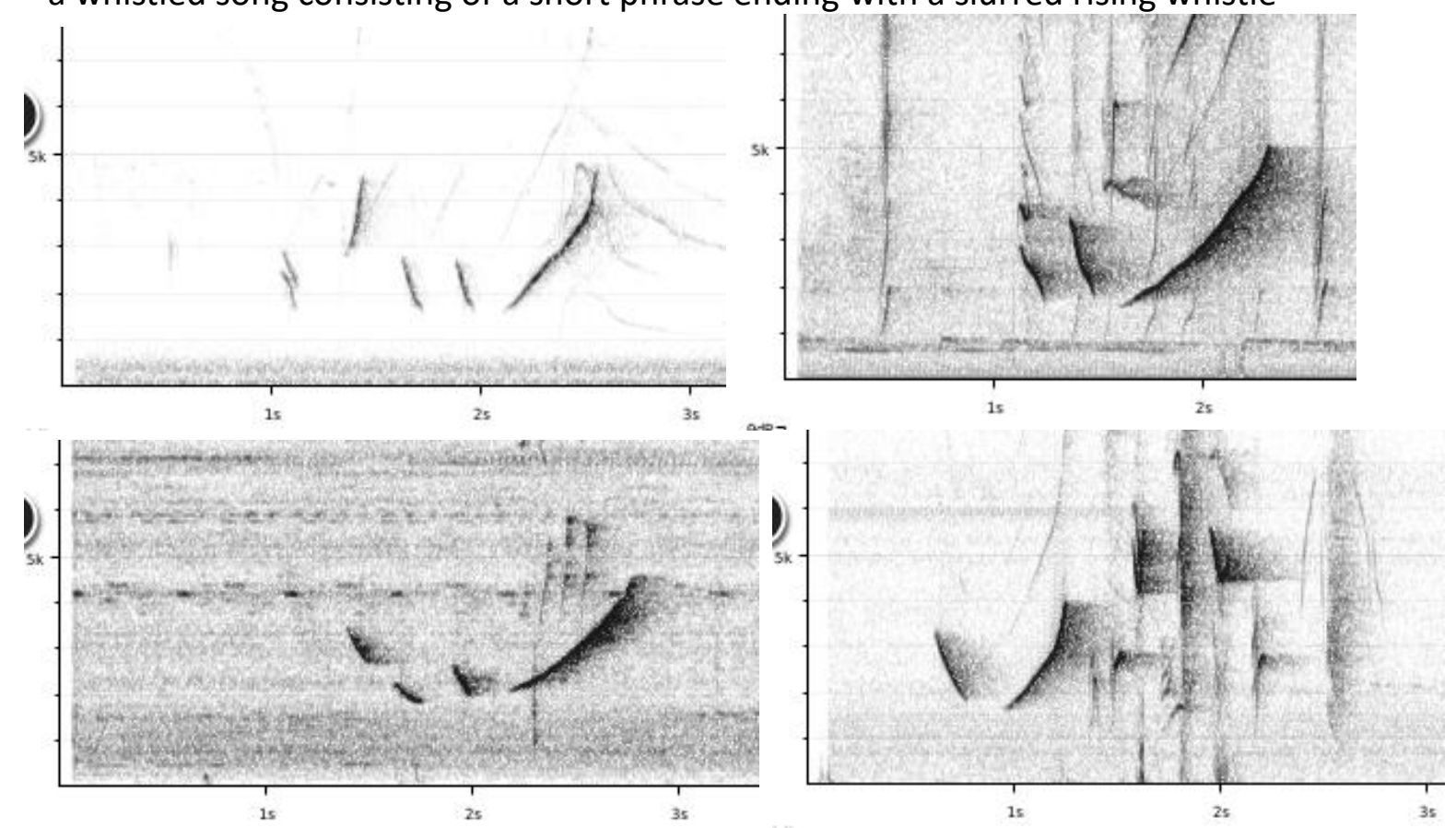

* a stuttering song which is typically longer in duration, consisting of many short notes

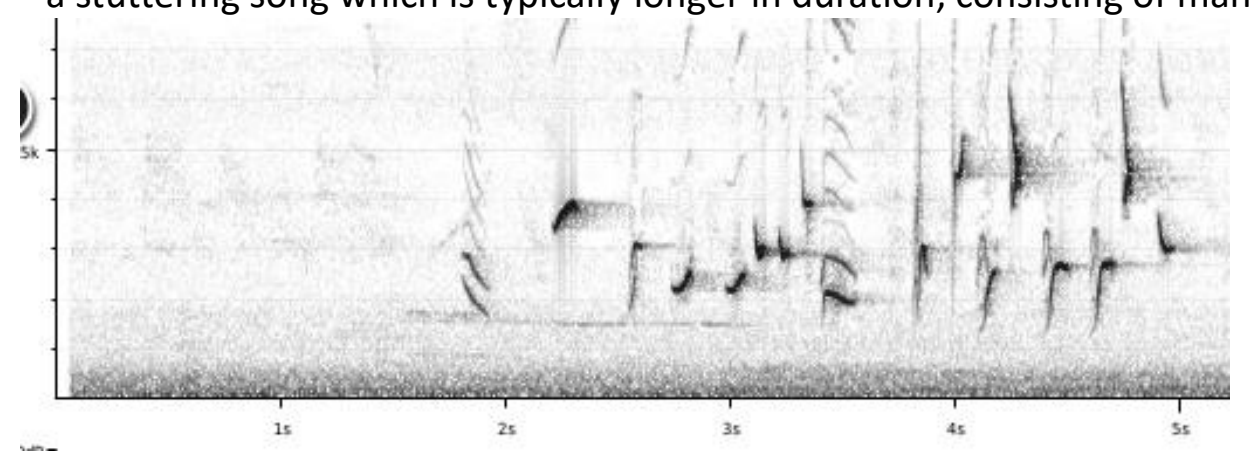




\section{HANDBOOK OF THE \\ Aluve}

\section{ORNITHOLOGICAL NOTES}

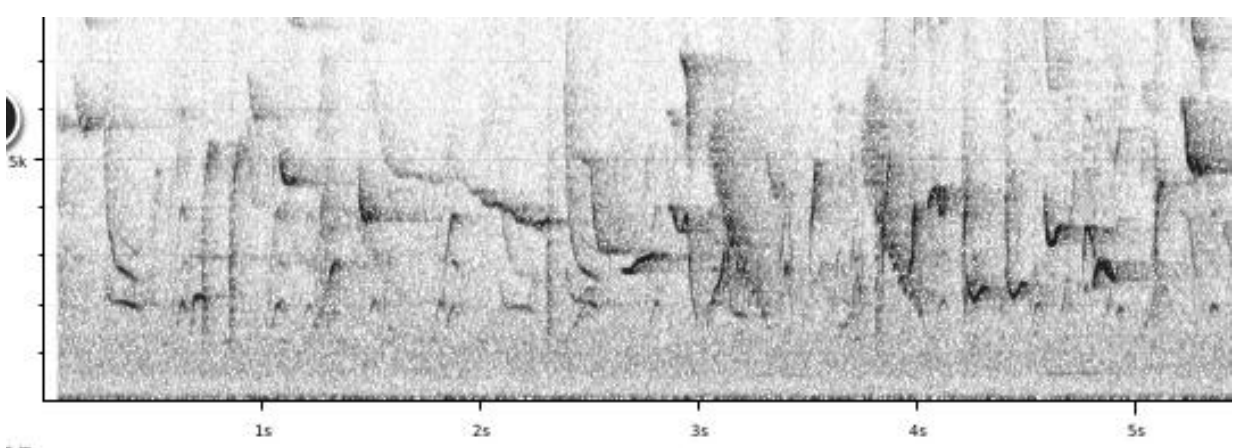

2. The Caribbean group (includes plumbeus, brewsteri and olivascens) This group has only a 'stuttering song' with rather harsh-sounding downslurred notes. Often with alternating high-pitched and low-pitched notes.

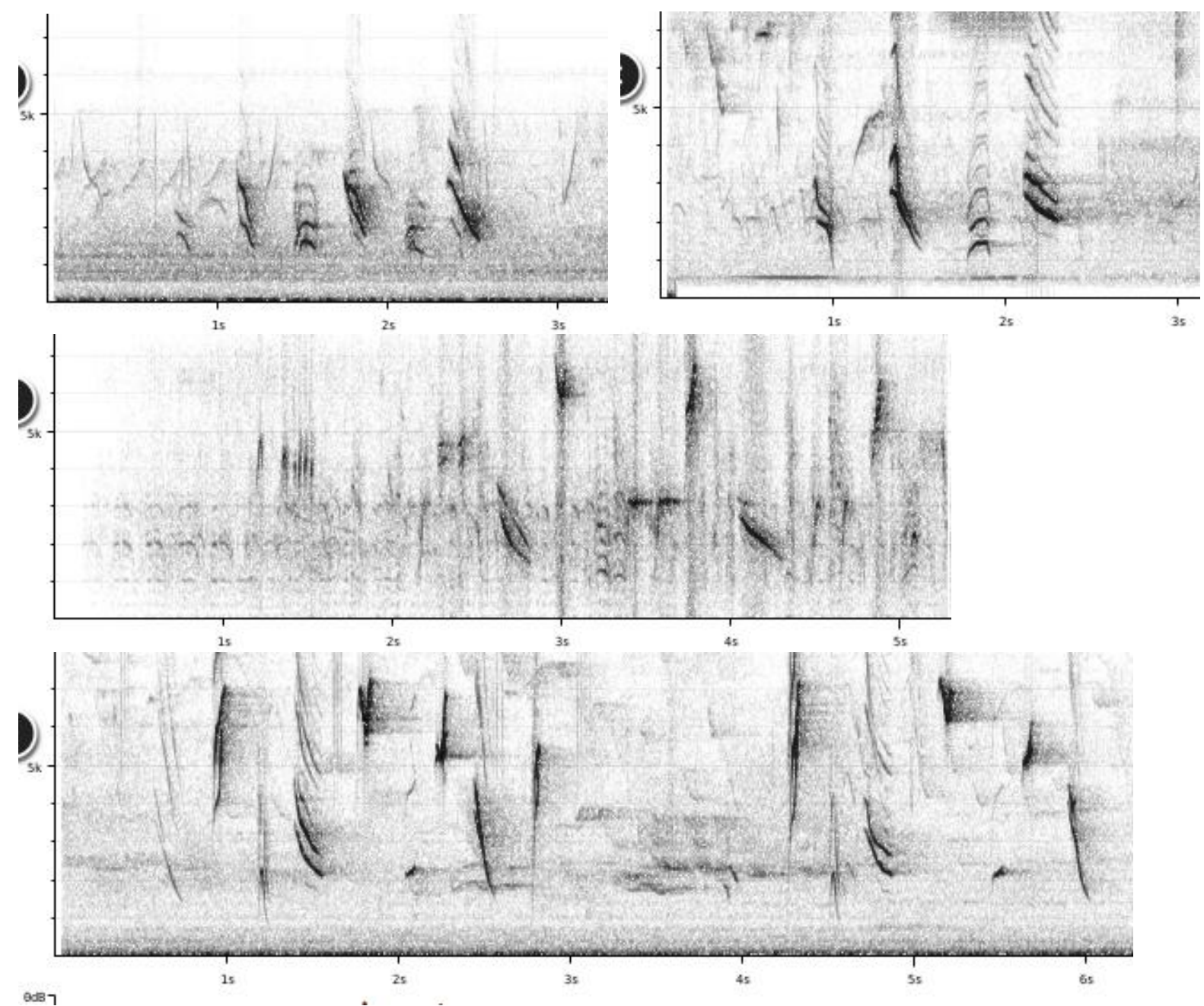




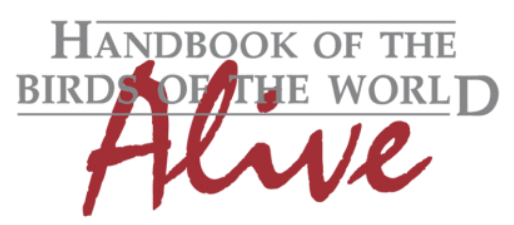

\section{ORNITHOLOGICAL NOTES}
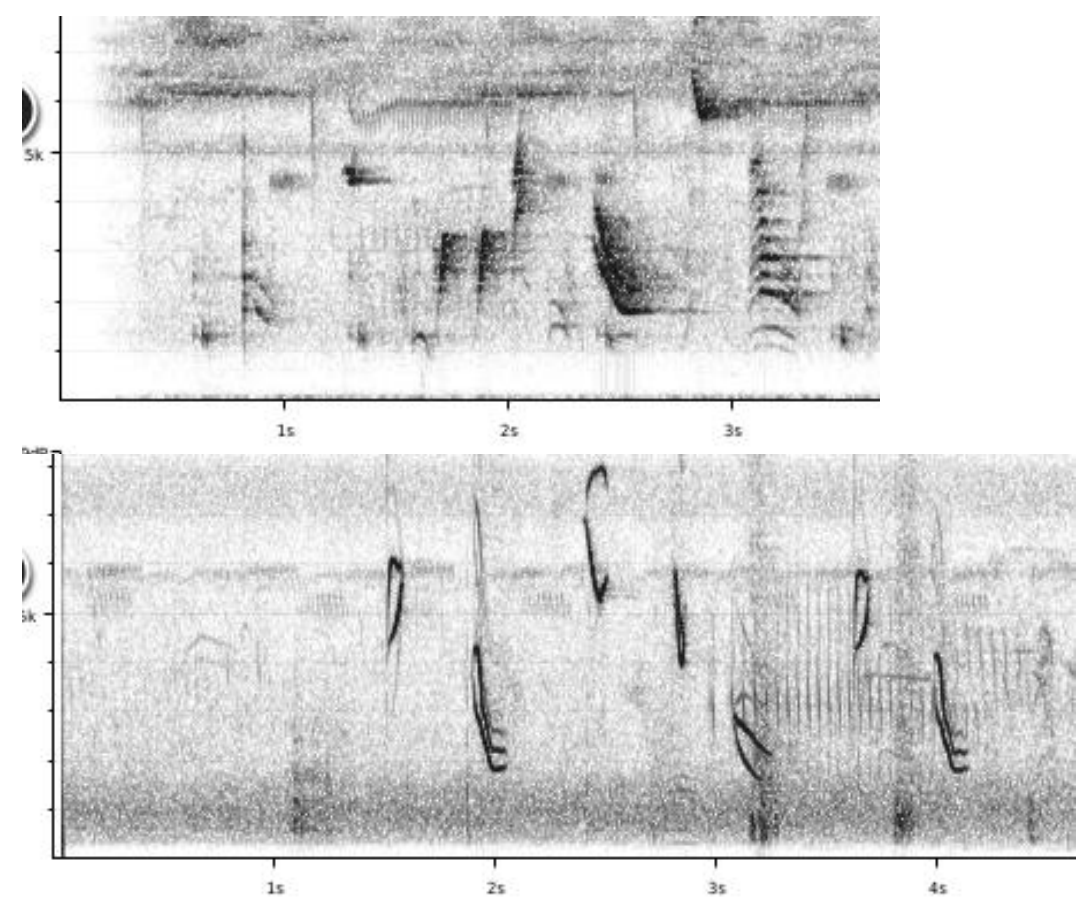

3. The Amazonian group (includes azarae, mutus, superciliaris and coerulescens) This group has two main song-like vocalizations:

* a whistled song consisting of a series of repeated mellow whistles, typically ending with a longer whistle (usually downslurred, sometimes burry and/or upslurred)
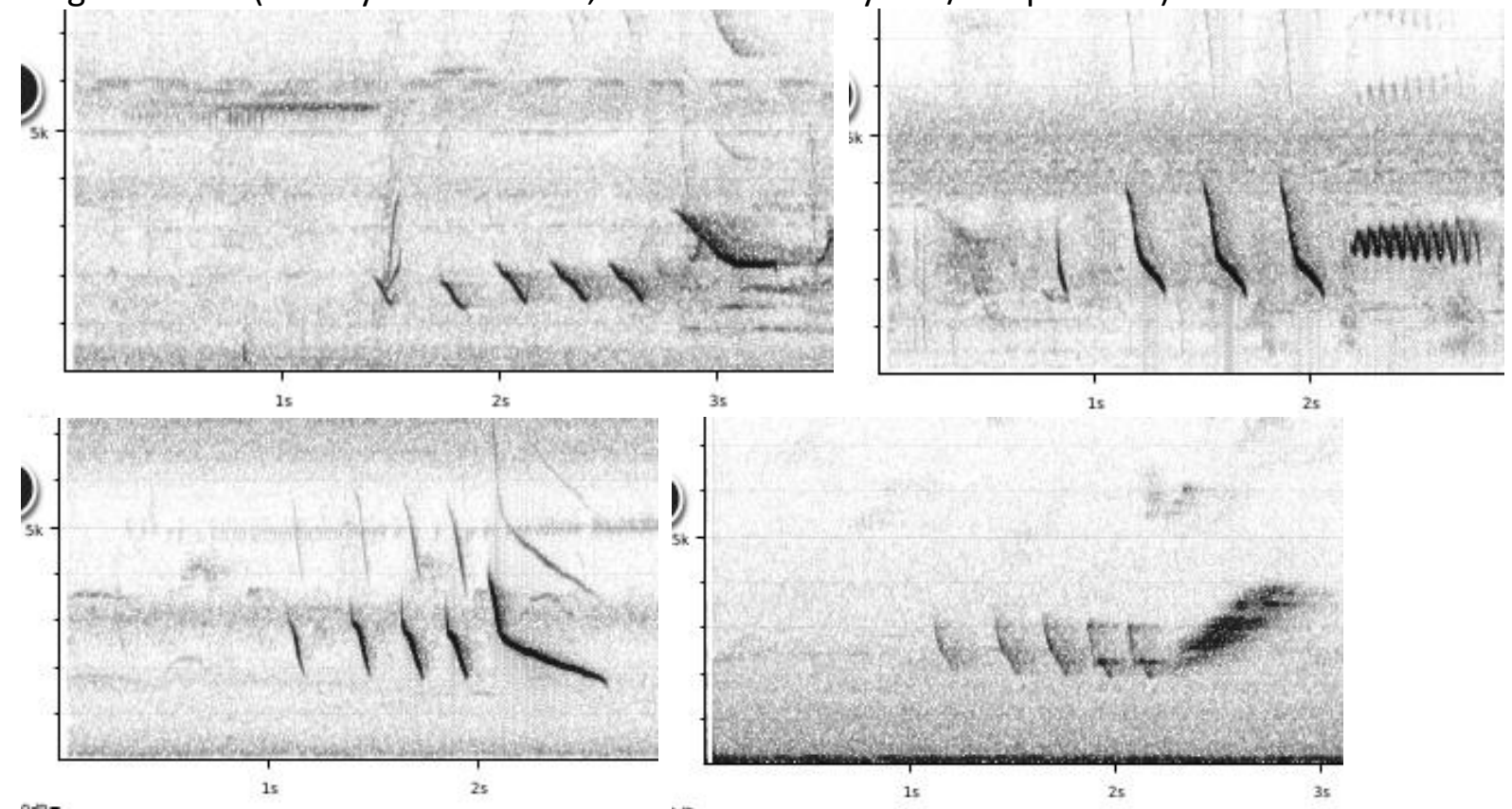

(Interestingly, this whistled song is closer to allopatric (northern) Streaked Saltator Saltator striatipectus, a relict from a common ancestor?). 


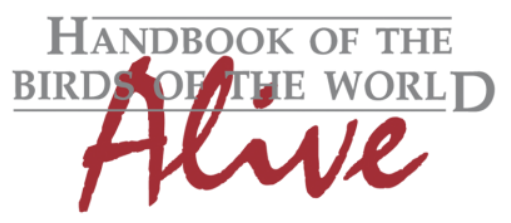

\section{ORNITHOLOGICAL NOTES}

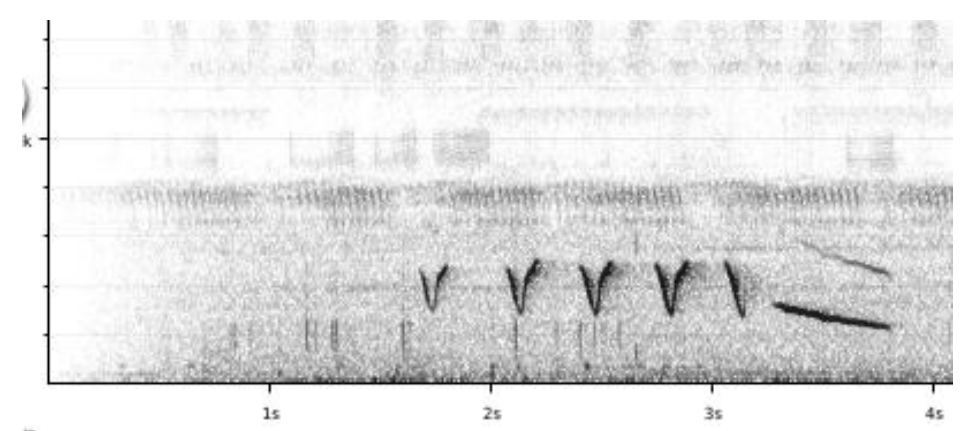

In west and south of range, sometimes more complex variations:
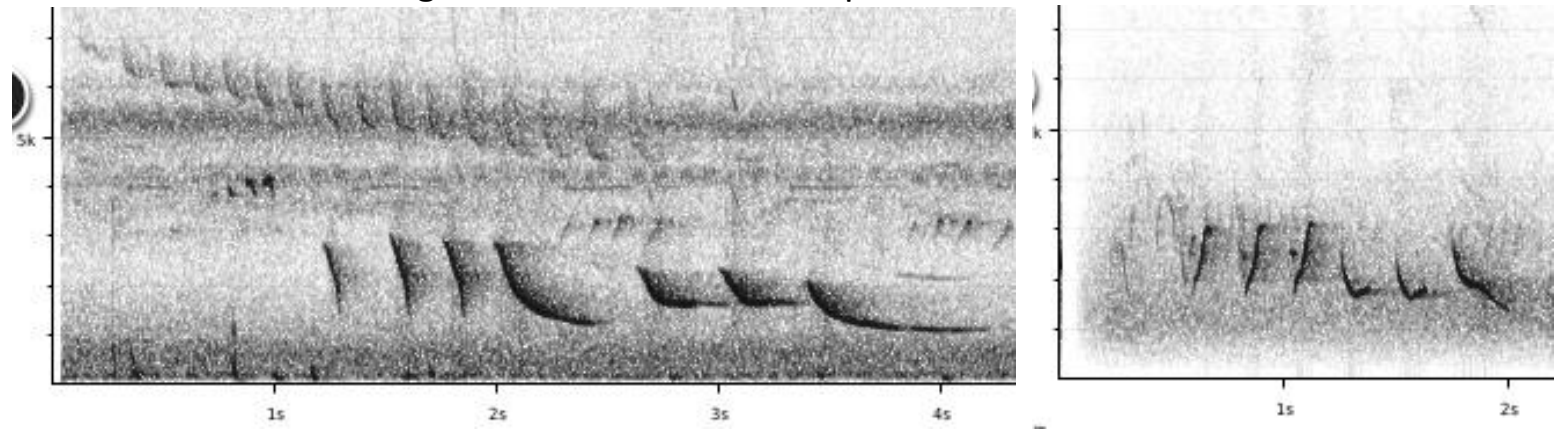

* a stuttered song consisting of a series of identical scolding notes, normally given as a duet with whistled song

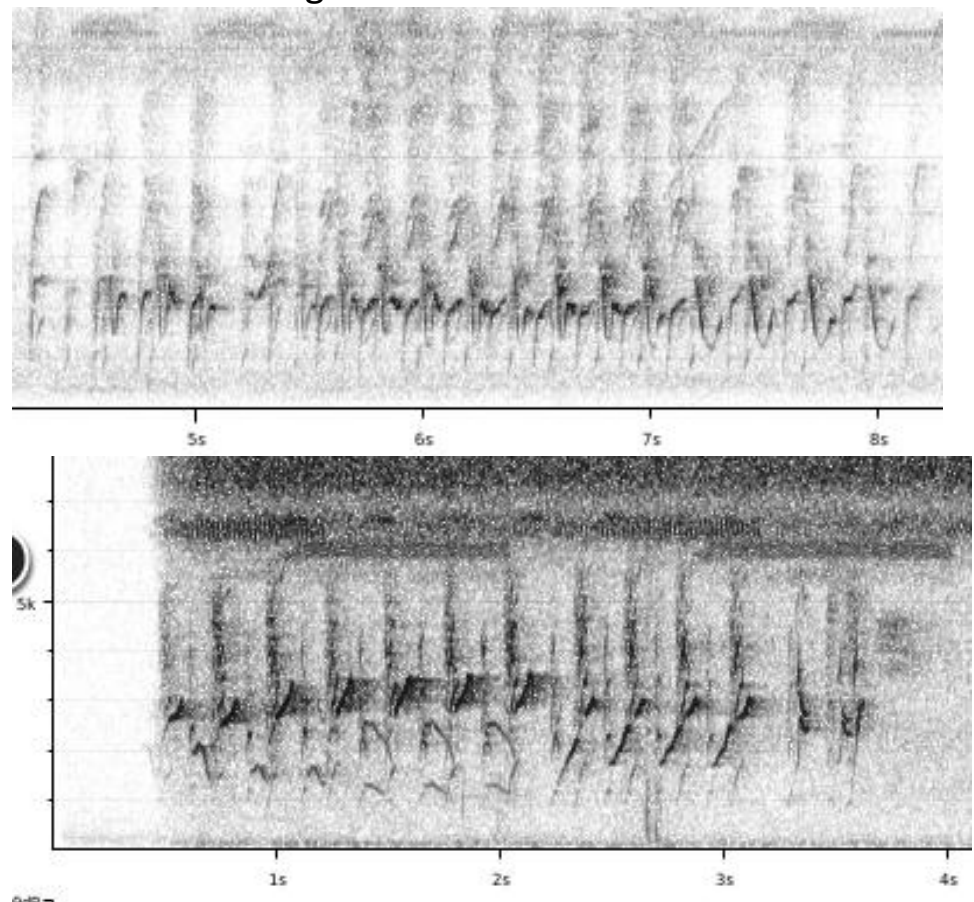

From the above overview, it is clear that we have three vocally very distinct groups.

While the Northern group has a disjunct range, the Caribbean and Amazonian group meet both in the west along the eastern foothills of the E Andes in Colombia, and in the east around the mouth of the Amazon.

Although there are very few recordings from E Colombia, the whistled song (Amazonian group) goes all the way north up to about Villavicencio along the $E$ slope of $E$ Andes 

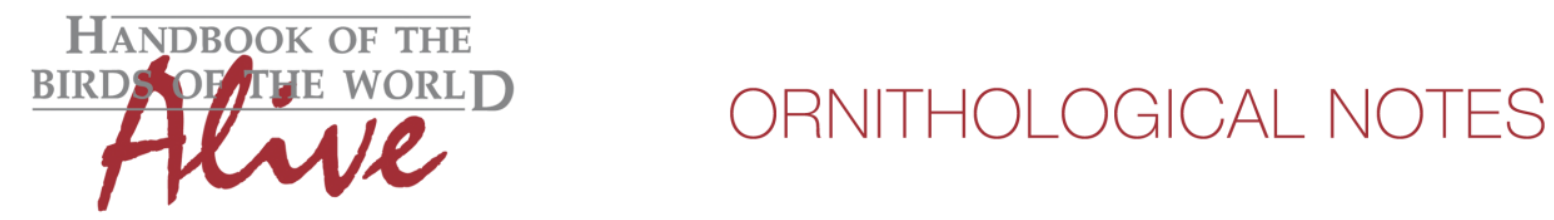

(XC327064/XC327455, provided these are correctly identified and not Streaked Saltator S. striatipectus), while just near the Venezuelan/Colombian border (XC245492) song is the Caribbean group type. There is thus likely parapatry somewhere along the river Meta near the Andes in Colombia.

In the delta region of the Amazon, there are even less recordings. There is however a single recording of NE French Guyana (XC142209) which seems to be of the 'whistled type' (while in Suriname song is Caribbean group type). It is thus most likely that mutus belongs to the Amazonian group (recordings from both sides of the Amazon around Manaus are also of this group), and there is thus the possibility of parapatry (or even sympatry??) somewhere in NE French Guyana. The fact that there is such a sudden change in voice both in the eastern and western extremities of the ranges of both groups is remarkable!

Vocal differences can be scored as follows:

The Caribbean group could be scored vs both other groups based on lack of long slurred notes (note length, score 3), lack of a second song type (2), slower pace of stuttered song (2), etc. (The fact that this group lacks a whistled song is possibly an adaptation to differentiate from the largely sympatric Streaked Saltator S. striatipectus). Application of Tobias criteria would lead to a total vocal score of about 5.

The Amazonian group could be scored vs the Northern group based on a stuttered song with repeated notes (\# of repeats, score 3 ) and a whistled song with less notes (2) and upslurred ending (2). Total score again about 5.

This note was finalized on 1st July 2016, using sound recordings available on-line at that moment. We would like to thank in particular the many sound recordists who placed their recordings for this species on XC.

\section{References}

Tobias, J.A., Seddon, N., Spottiswoode, C.N., Pilgrim, J.D., Fishpool, L.D.C. \& Collar, N.J. (2010). Quantitative criteria for species delimitation. Ibis 152(4): 724-746.

\section{Recommended citation}

Boesman, P. (2016). Notes on the vocalizations of Greyish Saltator (Saltator coerulescens). HBW Alive Ornithological Note 395. In: Handbook of the Birds of the World Alive. Lynx Edicions, Barcelona. (retrieved from http://www.hbw.com/node/1253584 on 1 December 2016). 